\title{
Left ventricular mass regression after aortic valve replacement with 17-mm St Jude Medical mechanical prostheses in isolated aortic stenosis
}

Cristiano Amarelli, MD

Alessandro Della Corte, MD

Gianpaolo Romano, MD

Gennaro Iasevoli, MD

Giovanni Dialetto, MD

Luca S. De Santo, MD

Marisa De Feo, MD

Michele Torella, MD

Michelangelo Scardone, MD

Maurizio Cotrufo, MD, FECTS

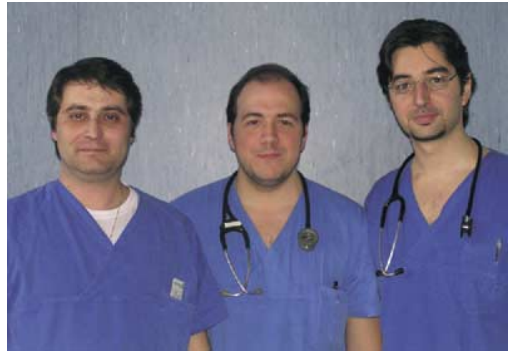

Romano, Amarelli, Della Corte (left to right)
From the Department of Cardiothoracic and Respiratory Sciences, Second University of Naples, V Monaldi Hospital, Naples, Italy.

Received for publication April 22, 2004; revisions received June 4, 2004; accepted for publication July 2, 2004.

Address for reprints: Cristiano Amarelli, MD, Via Cesario Console 3, 80132, Naples, Italy (E-mail: cristiano.amarelli@ospedalemonaldi. it).

J Thorac Cardiovasc Surg 2005;129:512-7 $0022-5223 / \$ 30.00$

Copyright (C) 2005 by The American Association for Thoracic Surgery

doi:10.1016/j.jtcvs.2004.07.007
Objective: The present study investigated the outcomes of aortic valve replacement with 17 -mm mechanical prostheses in patients with isolated aortic stenosis.

Methods: Between January 1997 and January 2003, 35 patients (mean age, $63.4 \pm 17$ years; median age, 70 years; age range, $16-84$ years) underwent isolated aortic valve replacement with a 17-mm St Jude Medical Hemodynamic Plus (16 [45.7\%] patients) or a St Jude Medical Regent prosthesis (19 [54.3\%] patients). The paired Student $t$ test or the paired Wilcoxon rank sum test were used to compare preoperative with follow-up echocardiographic measurements.

Results: Thirty-two (91.4\%) patients were female, mean height was $154.4 \pm 8.3 \mathrm{~cm}$, mean weight was $62.2 \pm 9.2 \mathrm{~kg}$, and mean body surface area was $1.59 \pm 0.13 \mathrm{~m}^{2}$. The preoperative average New York Heart Association class was $2.8 \pm 0.8$. The mean preoperative left ventricular mass index was $135.2 \pm 31 \mathrm{~g} / \mathrm{m}^{2}$. Preoperative echocardiography showed an average gradient of $65.7 \pm 19.2 \mathrm{~mm} \mathrm{Hg}$ (mean) and $103.6 \pm 30.7$ $\mathrm{mm} \mathrm{Hg}$ (peak) and a mean indexed effective orifice area of $0.40 \pm 0.1 \mathrm{~cm}^{2} / \mathrm{m}^{2}$. Echocardiographic follow-up time averaged 28.2 \pm 22.7 months (range, 13-72 months). Follow-up was $100 \%$ complete (1131.7 patient-months). Hospital mortality was $8.6 \%$ (3 patients). Actuarial 5-year survival was $94.7 \%$. The mean postoperative New York Heart Association class was $1.13 \pm 0.34(P<.001)$, with $27(87.1 \%)$ patients in class I and 4 patients in class II. A significant regression of the indexed left ventricular mass was found (postoperative mean value, $107.8 \pm 22.8 \mathrm{~g} / \mathrm{m}^{2} ; P<.0001$ ), despite a mean indexed effective orifice area of $0.67 \pm 0.14 \mathrm{~cm}^{2} / \mathrm{m}^{2}$ (median, $0.66 \mathrm{~cm}^{2} / \mathrm{m}^{2}$ ).

Conclusions: Selected patients with aortic stenosis can experience satisfactory clinical improvement and significant indexed left ventricular mass regression after aortic valve replacement with modern small-diameter bileaflet prostheses.

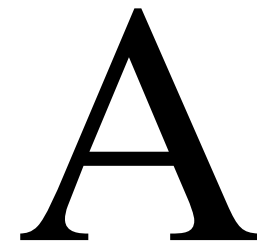

ortic valve replacement in patients with a small aortic root is still a challenge for the cardiac surgeon. Since 1978, when Rahimtoola ${ }^{1}$ first pointed out the threat of poor outcome in patients receiving small aortic prostheses, an intense debate has developed on this topic without a uniform conclusion. Although some studies ${ }^{2-4}$ have suggested the possibility that the increased morbidity and mortality in this subset of patients has to be mainly ascribed to patient-related factors rather than valve-related factors, others ${ }^{5-8}$ show a significant 
relationship between patient-prosthesis mismatch (PPM) and clinical outcome. Some studies ${ }^{6}$ have shown decreased symptom relief, poor regression of left ventricular mass, and decreased survival with an indexed effective orifice area (EOAI) of less than $0.85 \mathrm{~cm}^{2} / \mathrm{m}^{2}$, whereas others ${ }^{5}$ have shown such results with an EOAI of less than $0.75 \mathrm{~cm}^{2} / \mathrm{m}^{2}$.

Several surgical strategies can be applied to avoid the feared PPM. These strategies include the use of root-enlargement procedures, stentless bioprostheses, or modern mechanical valves with an improved hemodynamic profile. Reports about the effect of some of these strategies fail to point uniformly toward an improved outcome. ${ }^{9}$ Authoritative reports have demonstrated a marked, although not statistically significant, early mortality increase after aortic root-enlargement procedures ${ }^{9}$ without a superiority in longterm results and therefore suggested the use of stentless prostheses in the small aortic root. In contrast, other authors ${ }^{10}$ have claimed minimal added 30-day risk with root enlargement when compared with isolated aortic valve replacement. Results from different randomized comparisons between stented and stentless bioprostheses have failed to show a uniform conclusion: some studies ${ }^{11,12}$ show equal performance between the 2 types of prostheses, whereas others $^{13}$ show a superior performance of stentless biologic valves. Prospective investigations evaluating clinical outcomes of stentless aortic valve replacement in patients with a small aortic annulus are lacking. Some authors have shown the superiority of mechanical over biologic prostheses in this patient subset. ${ }^{5}$ Good results are reported, especially when bileaflet prostheses with improved hemodynamics $^{14-16}$ are implanted. The aim of this study was to evaluate the short-term clinical and echocardiographic outcomes of aortic valve replacement with $17-\mathrm{mm}$ St Jude Medical mechanical prostheses (Hemodynamic Plus [HP] and Regent models; St Jude Medical, Inc, St Paul, Minn) in a population of patients referred to our center for aortic valve stenosis. Characteristics of our study population were in accordance with those of populations studied in other series, ${ }^{17,18}$ showing that patients in whom the option of a small aortic prosthesis for aortic valve replacement is feasible are mostly small elderly women.

\section{Patients and Methods}

\section{Study Population}

Between January 1997 and January 2003, 1235 isolated aortic valve replacement procedures with mechanical prostheses were performed in our hospital. A 17-mm St Jude Medical valve was implanted in 55 (4.4\%) cases: from 1997 through 2000, 27 patients received an HP model, and between 2001 and 2003, 28 had a Regent model implanted. Of those 55 cases, 20 patients with associated procedures (other than coronary artery bypass grafting) were excluded, and thus 35 patients entered the study. Among them, $32(91.4 \%)$ were female, with a mean age of $63.4 \pm 17$ years (median age, 70 years; age range, 16-84 years) and a mean body
TABLE 1. Preoperative data

\begin{tabular}{|c|c|}
\hline $\begin{array}{l}\text { Age (y), mean } \pm \text { SD (median } \\
\text { [range]) }\end{array}$ & $63.4 \pm 17(70[16-84])$ \\
\hline $\begin{array}{l}\text { Height }(\mathrm{cm}) \text {, mean } \pm \mathrm{SD} \text { (median } \\
\text { [range]) }\end{array}$ & $154.4 \pm 8.3(155[136-173])$ \\
\hline $\begin{array}{l}\text { Weight }(\mathrm{kg}) \text {, mean } \pm \mathrm{SD} \text { (median } \\
\text { [range]) }\end{array}$ & $62.2 \pm 9.2(62[40-85])$ \\
\hline $\begin{array}{l}\mathrm{BSA}\left(\mathrm{m}^{2}\right) \text {, mean } \pm \mathrm{SD} \text { (median } \\
\text { [range]) }\end{array}$ & $1.59 \pm 0.13(1.59[1.21-1.80])$ \\
\hline $\begin{array}{l}\mathrm{BMI} \text {, mean } \pm \mathrm{SD} \text { (median } \\
\text { [range]) }\end{array}$ & $26.42 \pm 4.53(25.8[20.13-37.78])$ \\
\hline \multicolumn{2}{|l|}{ NYHA class } \\
\hline I & $3(8.6 \%)$ \\
\hline II & $6(17.1 \%)$ \\
\hline III & $21(60 \%)$ \\
\hline IV & $3(8.6 \%)$ \\
\hline Cardiogenic shock & $2(5.7 \%)$ \\
\hline Female sex & $32(91.4 \%)$ \\
\hline \multicolumn{2}{|l|}{ Aortic valve disease } \\
\hline Degenerative & $22(62.9 \%)$ \\
\hline Congenital & $10(28.6 \%)$ \\
\hline Rheumatic & $2(5.4 \%)$ \\
\hline Other & $1(2.9 \%)$ \\
\hline Hypertension & $21(60 \%)$ \\
\hline Diabetes & $4(11.6 \%)$ \\
\hline Obesity & $7(20 \%)$ \\
\hline Atherosclerosis & $4(11.6 \%)$ \\
\hline Severely calcified annulus & $25(71.4 \%)$ \\
\hline $\begin{array}{l}\text { EuroSCORE, mean } \pm \text { SD (median } \\
\text { [range]) }\end{array}$ & $4.45 \pm 2.95(4[0-14])$ \\
\hline
\end{tabular}

BSA, Body surface area; $B M I$, body mass index; NYHA, New York Heart Association.

surface area (BSA) of $1.59 \pm 0.13 \mathrm{~m}^{2}$. Anthropometric features are shown in Table 1. All 35 patients underwent operations for an isolated aortic stenosis. Symptoms at admission included angina in $31.4 \%$ of patients and syncope or arrhythmia in $8.6 \%$ of patients. In 3 asymptomatic patients a surgical procedure was indicated for calcific appearance of the stenotic valve at echocardiography ${ }^{19}$ and high transvalvular gradients. Mean preoperative New York Heart Association class was $2.8 \pm 0.8$. Preoperative clinical features are shown in Table 1 . The incidence of associated coronary atherosclerosis was $11.4 \%$, as detected by means of coronary arteriography, and peripheral atherosclerosis (involvement of the supraaortic vessels or lower-limb arteries) was found in $8.6 \%$. The most common cause of the aortic stenosis was degenerative $(62.9 \%)$. Three $(8.6 \%)$ patients had previously undergone cardiac surgery. Mean EuroSCORE (calculated according to the additive EuroSCORE model $^{20}$ ) in the present study population was $4.45 \pm 2.95$.

\section{Echocardiography}

Standard M-mode dimensions were collected according to the criteria of the American Society of Echocardiography. All Doppler measurements were obtained as the average of at least 3 cycles in patients with sinus rhythm or more than 5 cycles in those with atrial fibrillation. The peak and mean gradients across the prosthesis were calculated according to the modified Bernoulli equation. 
Table 2. Echocardiographic preoperative and postoperative data

\begin{tabular}{lcrr}
\hline & Preoperative & Follow-up & \multicolumn{1}{c}{} \\
\hline Maximum gradient & $103.6 \pm 30.7(100[45-124])$ & $36.8 \pm 12.2(38.5[18-61])$ & $<.001$ \\
Mean gradient & $65.7 \pm 19.2(68[25-76])$ & $21.8 \pm 7.8(22.5[11-37])$ & $<.001$ \\
LVMI & $135.2 \pm 31(135.1[73-144])$ & $107.8 \pm 22.8(103[70-188.6])$ & $<.001$ \\
EOA & $0.63 \pm 0.18(0.63[0.41-1.05])$ & $1.05 \pm 0.24(1.04[0.58-1.63])$ & $<.001$ \\
EOAI & $0.40 \pm 0.10(0.39[0.22-0.59])$ & $0.67 \pm 0.14(0.66[0.47-0.97])$ & $<.001$ \\
EF & $58.1 \pm 12.6(60[25-70])$ & $59.2 \pm 6(60[50-75])$ & .545 \\
\hline
\end{tabular}

All data are presented as means \pm SD (median [range]). LVMI, Left ventricular mass index; EOA, effective orifice area; EOAI, effective orifice area index; $E F$, ejection fraction.

*Paired $t$ test.

The effective orifice area was calculated by using the mean of the continuity equation: $\left(\mathrm{LVOT}^{2} \times 0.785 \times \mathrm{TVI}_{1}\right) / \mathrm{TVI}_{2}$, where LVOT is the diameter of the left ventricular outflow tract and $\mathrm{TVI}_{1}$ and $\mathrm{TVI}_{2}$ are the time-velocity integrals at the left ventricular outflow tract and across the aortic valve respectively. The left ventricular mass index (LVMI) was calculated from Reichek's formula. ${ }^{21}$ BSA was calculated according to the Dubois formula. Preoperative echocardiography was available in $100 \%$ of patients. Preoperative ejection fraction (EF) averaged $58.1 \% \pm 13 \%$, with 3 patients having a preoperative EF of less than $40 \%$. Mean preoperative LVMI was $135.2 \pm 31 \mathrm{~g} / \mathrm{m}^{2}$. Preoperative hemodynamic data, as detected at transthoracic echocardiography, are reported in Table 2 .

\section{Surgical Technique}

The operation was always performed through a median sternotomy, with moderate systemic hypothermia and use of cold potassium cardioplegia and pericardial topical cooling. Prosthesis size was selected according to the size of the aortic annulus, which was determined by using the manufacturer's sizer. In 2 cases, for technical reasons, a 17-mm prosthesis was implanted, although the manufacturer's sizer indicated a 19-mm annulus size. Prostheses were implanted with single interrupted sutures. Regent model prostheses were implanted supra-annularly. Teflon pledgets were used when needed (5.7\% of cases). Valve prostheses were implanted with their axis perpendicular to the interventricular septum. Implanted prostheses were St Jude Medical HP in 16 (45.7\%) patients and SJM Regent in $19(54.3 \%)$ patients. The annulus was severely calcified in $71.4 \%$ of cases, and additional surgical debridement of the left ventricular outflow tract, the anterior mitral leaflet, and/or the left coronary ostium was performed in $20.4 \%$ of cases. Coronary artery bypass grafting procedures were associated in $5(14.5 \%)$ patients.

After the second postoperative day, patients received oral anticoagulation with sodium warfarin at daily updated dosages according to international normalized ratios. The target international normalized ratio value was in accordance with American College of Cardiology/American Heart Association guidelines.

\section{Follow-up}

Patients were followed up by the cardiologists of our echocardiography outpatient clinic at a mean postoperative time point of $28.2 \pm 22.7$ months (median, 21.6 months; range, 13-72 months).
Both clinical (New York Heart Association class evaluation) and echocardiographic (maximum and mean gradients, EOAI, and LVMI) assessments were scheduled by protocol at the sixth postoperative month and yearly thereafter. Clinical follow-up was updated to May 2004 through telephone interview for all patients. In case of new-onset symptoms, additional echocardiography examinations were performed, and the patient's follow-up charts were updated accordingly.

Echocardiographic follow-up was $100 \%$ complete. Definition of valve-related events and anticoagulation-related complications was made according to Edmunds' criteria.

\section{Statistical Analysis}

The SPSS software (version 10.1; SPSS Inc, Chicago, Ill) was used for statistical analysis. Continuous variables were expressed as means $\pm \mathrm{SD}$, whereas categorical variables were expressed as counts and percentages. The paired Student $t$ test or the paired Wilcoxon rank-sum test in case of asymmetric distributed data was used to compare echocardiographic data measured preoperatively with those found at follow-up. Actuarial survival was calculated by using the mean of the Kaplan-Maier method and expressed as percentages $\pm \mathrm{SE}$.

\section{Results}

\section{Clinical Follow-up and Valve-Related Events}

Clinical follow-up showed an actuarial survival of $88.6 \% \pm$ $0.07 \%$ at 5 years (mean follow-up time, $35.4 \pm 22.3$ months; 1131.7 patient-months). Three patients died within 30 days of the operation (hospital mortality, 8.6\%). In 2 cases death occurred soon after the operation because of low cardiac output syndrome. One patient who postoperatively had a stroke died of respiratory failure. The early postoperative period was complicated in 1 patient by bleeding requiring surgical revision and in another patient by atrioventricular block requiring pacemaker implantation. One female 82-year-old patient died 1 year postoperatively of complications of an amyotrophic lateral sclerosis. There was no structural failure of the prostheses, no paravalvular leak, and no prosthetic endocarditis. Freedom from reoperation was $100 \%$. No valve-related or anticoagulation-related 
complications were recorded. Figure 1 shows data about preoperative and postoperative clinical status.

\section{Echocardiographic Follow-up}

Echocardiographic results are displayed in Table 2. A significant reduction in maximum and mean gradients was observed in all patients, with a mean difference versus preoperative values of $66.8 \pm 25.6 \mathrm{~mm} \mathrm{Hg}$ (95\% confidence interval $[\mathrm{CI}], 57.4-76.3)$ and $43.9 \pm 19 \mathrm{~mm} \mathrm{Hg}(95 \% \mathrm{CI}$, 36.9-49.8), respectively. A statistically significant reduction in mean ventricular mass values was found $(P<.0001)$, with a mean difference of $27.4 \pm 25.7 \mathrm{~g} / \mathrm{m}^{2}(95 \% \mathrm{CI}$, 16.5-36.1). Only in 4 (12.5\%) patients did LVMI increase postoperatively. In 19 female and 3 male patients (68.7\%) LVMI normalized. In $5(15.6 \%)$ patients postoperative LVMI ranged between 110 and $125 \mathrm{~g} / \mathrm{m}^{2}$. In the other 5 patients postoperative LVMI was greater than $125 \mathrm{~g} / \mathrm{m}^{2}$.

No significant difference between preoperative and postoperative mean EF was observed. In the 3 patients with preoperative $\mathrm{EF}$ of less than $40 \%$, ventricular function showed a trend toward recovery to normal values postoperatively.

\section{Discussion}

Hospital mortality in our series is consistent with that of published studies on similar patient populations receiving small-diameter mechanical prosthetic valves, ${ }^{17,22}$ which is, however, a higher rate than generally reported for aortic valve replacement. In a large series by Blackstone and colleagues ${ }^{23}$ patient prosthesis size of less than $1.2 \mathrm{~cm}^{2} / \mathrm{m}^{2}$ was associated with a $1 \%$ to $2 \%$ increase in 30-day mortality. A recent study by Blais and associates ${ }^{8}$ demonstrated that PPM is a risk factor for in-hospital mortality, with the most prevalent cause of death being low-output syndrome. This was the cause of death in 2 of the 3 patients who died in the hospital in the present report. However, our mortality rate of $8.6 \%$ could also be explained by the relatively high mean and median preoperative EuroSCORE values. In a large series of geriatric patients, ${ }^{24}$ the use of small valves was not an independent risk factor for early mortality, whereas small BSA was among the significant predictors of hospital death. In the present study only 2 models of the St Jude Medical mechanical bileaflet prosthesis were implanted. The St Jude Medical Regent model, when compared with the same size St Jude Medical HP model, shows increased orifice dimensions because of modified external geometry of the orifice housing. ${ }^{25}$ Despite good in vivo performance, ${ }^{16,26}$ clear evidence of the long-term clinical superiority of the Regent model has not yet emerged. In the present study no significant difference was found in terms of preoperative and follow-up LVMI between the 2 models implanted, probably because of the exiguity of the subpopulations.

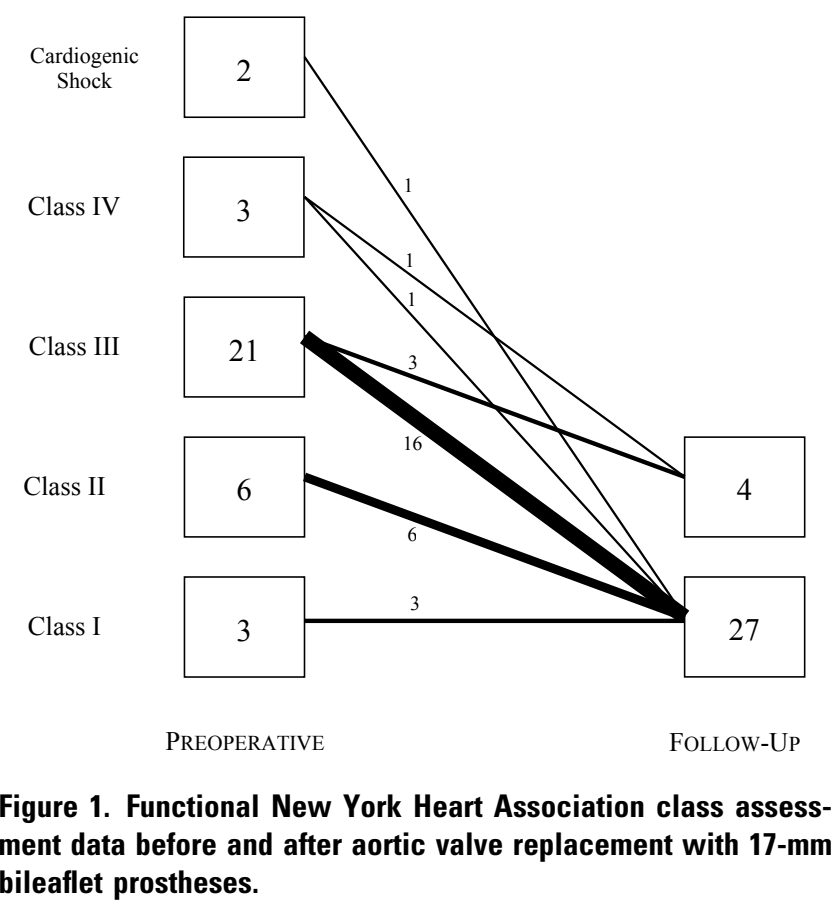

In an authoritative editorial ${ }^{4}$ commenting on the favorable experience of Sawant and coworkers ${ }^{18}$ with small mechanical prostheses, the role of patient baseline characteristics was emphasized. Medalion and associates, ${ }^{3}$ reporting on a series of 892 patients, maintained that survival after aortic valve replacement might be related to patient risk factors but not adversely affected by moderate PPM. Patients with associated aortic valve regurgitation or mitral valve disease were excluded from the present study in an attempt to minimize the effect on left ventricular mass regression of associated conditions that were considered, in a critical article by Christakis and Goldman, ${ }^{4}$ a source of sample heterogeneity and therefore of relevant bias. As far as hypertension is concerned, it was present in about $60 \%$ of our patients: all of them were postoperatively treated with antihypertensive drugs, and blood pressure control was satisfactory (normal values or sporadic mild hypertension at each follow-up visit and telephone interview). Our study population presented with high mean age and was characterized by low daily physical activity (the patient aged 16 years was affected by Turner syndrome and chronic renal failure treated with hemodialysis) and very low mean height. Although the mean BSA could be considered not so low, with body mass index values being relatively high, it has been previously pointed out that the annular diameter relates significantly better to height than to $\mathrm{BSA} .{ }^{27} \mathrm{~A}$ mean EOAI of 0.67 could probably determine a more severe mismatch in taller patients with the same BSA.

The most interesting result of this study was the significant regression of mean LVMI, despite the realization of a moder- 
ate degree of PPM (with an EOAI of $<0.65$ in $41 \%$ of patients), consistently with transprosthetic maximum gradients that are reasonable for small-diameter prostheses (mean and median, $22 \mathrm{~mm} \mathrm{Hg}$ ). The reliability of Doppler measurements of transprosthetic gradients has been reconsidered by some authors, ${ }^{28}$ showing that the particular transprosthetic flow and velocity distribution could induce an overestimation of the values when compared with invasive methods. Patients not showing a complete regression of LVMI should undergo deeper investigations. Freed and colleagues, ${ }^{17}$ in a population of small, elderly patients, explained the excellent results in terms of mass regression with their low preoperative LVMI $\left(114 \mathrm{~g} / \mathrm{m}^{2}\right)$. Although our patients' mean preoperative LVMI value did not represent an impressive left ventricular hypertrophy grade, $135 \mathrm{~g} / \mathrm{m}^{2}$ is to be considered high for a predominantly female population, also in view of the very low mean height. Indeed, in some of our patients, a delay in surgical referral might have occurred: this is revealed by the high prevalence of severely calcified annulus ( $71.4 \%$ of patients) that should represent an indication for surgical intervention in an asymptomatic elderly patient. ${ }^{19}$ Preoperative functional status was quite poor, implying a high prevalence of advancedstage disease with diastolic dysfunction. In 3 patients systolic dysfunction ( $\mathrm{EF}<45 \%$ ) was present also. With these baseline conditions, the possibility of complete left ventricular regression is questionable because interstitial relative fibrosis is supposed to be preoperatively increased. ${ }^{29}$ Stratification on the basis of preoperative clinical status could be useful but was not feasible in this study because of the small sample dimensions.

As regards clinical outcomes of aortic valve replacement with 17-mm St Jude Medical prostheses, we observed good functional recovery in most patients, which is consistent with the data about LVMI regression. Our clinical results seem to be in discordance with those most recently forwarded by Ruel and coworkers, ${ }^{30}$ claiming that PPM is a significant predictor of postoperative congestive heart failure symptoms. Unfortunately, because of the different follow-up lengths and the lack of any LVMI regression analysis in that study, it is not possible to make comparisons with our study, which merely addressed the occurrence of mass regression early after aortic valve replacement with $17-\mathrm{mm}$ prostheses. It has been stated ${ }^{4}$ that aortic valve replacement with a small bileaflet prosthesis could be viewed as the substitution of a progressive disease with another nonphysiologic condition that is, however, steadily persistent and less severe. Further investigations on larger series of aortic valve replacement, including all possible PPM degrees, should be undertaken to assess which are the determinants of LVMI regression or increase.

Some limitations of this study should be considered. The retrospective approach to data collection might have entailed an imponderable methodologic bias. The routine echocardiographic and clinical controls were not always precisely attended by the patients at the scheduled time intervals: this jeopardized the possibility of assessing the influence of time on LVMI regression. Similarly, because the 2 models were not implanted concurrently and a relevant number of early follow-up data were unavailable for the HP subgroup, no comparative evaluation between the 2 prosthetic models could be performed. A prospective design would have allowed for repeated-measurements analysis of variance on standardized time-interval examinations. Furthermore, M-mode echocardiography is surely less accurate than magnetic resonance imaging in the measurement of LVMI; however, the unavailability of preoperative magnetic resonance imaging in our patients prevented any comparison with possible postoperative data. No exercise test was performed because such an elderly study population as ours is expected to have limited daily physical activity, and the significance of valve performance at exertion in the perspective of postoperative quality-of-life assessment is thereby questionable.

\section{References}

1. Rahimtoola S. The problem of valve prosthesis-patient mismatch. Circulation. 1978;58:20-4.

2. Hanayama N, Christakis GT, Mallidi HR, Joyner CD, Fremes SE, Morgan CD, et al. Patient prosthesis mismatch is rare after aortic valve replacement: valve size may be irrelevant. Ann Thorac Surg. 2002;73: 1822-9.

3. Medalion B, Blackstone EH, Lytle BW, White J, Arnold JH, Cosgrove DM. Aortic valve replacement: is valve size important? J Thorac Cardiovasc Surg. 2000;119:963-74.

4. Christakis GT, Goldman BS. Do small aortic valves influence longterm survival? Ann Thorac Surg. 1997;63:933-4.

5. Rao V, Jamieson WRE, Ivanov J, Armstrong S, David TE. Prosthesispatient mismatch affects survival following aortic valve replacement. Circulation. 2000;102(suppl III):III5-9.

6. Pibarot P, Dumesnil JG, Cartier PC, Metras J, Lemieux MD. Patientprosthesis mismatch can be predicted at the time of operation. Ann Thorac Surg. 2001;71(suppl 5):S265-8.

7. Pibarot P, Dumesnil JG, Lemieux M, Cartier P, Metras J, Durand LG. Impact of prosthesis-patient mismatch on hemodynamic and symptomatic status, morbidity and mortality after aortic valve replacement with a bioprosthetic heart valve. J Heart Valve Dis. 1998;7:211-8.

8. Blais C, Dumesnil JG, Baillot R, Simard S, Doyle D, Pibarot P. Impact of valve prosthesis-patient mismatch on short-term mortality after aortic valve replacement. Circulation. 2003;108:983-8.

9. Sommers KE, David TE. Aortic valve replacement with patch enlargement of the aortic annulus. Ann Thorac Surg. 1997;63:1608-12.

10. Castro LJ, Arcidi JM Jr, Fisher AL, Gaudiani VA. Routine enlargement of the small aortic root: a preventive strategy to minimize mismatch. Ann Thorac Surg. 2002;74:31-6.

11. Doss M, Martens S, Wood JP, Aybek T, Kleine P, Wimmer Greinecker $\mathrm{G}$, et al. Performance of stentless versus stented aortic valve bioprostheses in the elderly patient: a prospective randomized trial. Eur J Cardiothorac Surg. 2003;23:299-304.

12. Cohen G, Christakis GT, Joyner CD, Morgan CD, Tamariz M, Hanayama N, et al. Are stentless valves hemodynamically superior to stented valves? A prospective randomized trial. Ann Thorac Surg. 2002;73:767-78.

13. Walther T, Falk V, Langebartels G, Kruger M, Bernhardt U, Diegeler A, et al. Prospectively randomized evaluation of stentless versus conventional biological aortic valves: impact on early regression of left ventricular hypertrophy. Circulation. 1999;100(suppl II):II6-10. 
14. Izzat MB, Kadir I, Reeves B, Wilde P, Bryan AJ, Angelini GD. Patient-prosthesis mismatch is negligible with modern small-size aortic valve prostheses. Ann Thorac Surg. 1999;68:1657-60.

15. Vitale N, Caldarera I, Muneretto C, Sinatra R, Scafuri A, Di Rosa E, et al. Jude Medical Hemodynamic Plus Aortic Valve Prosthesis. Clinical evaluation of St Jude Medical Hemodynamic Plus versus standard aortic valve prostheses: The Italian multicenter, prospective, randomized study. J Thorac Cardiovasc Surg. 2001;122:691-8.

16. Gelsomino S, Morocutti G, Da Col P, Frassani R, Carella R, Minen G, et al. Preliminary experience with the St. Jude Medical Regent mechanical heart valve in the aortic position: early in vivo hemodynamic results. Ann Thorac Surg. 2002;73:1830-6.

17. Freed DH, Tam JW, Moon MC, Harding GE, Ahmad E, Pascoe EA. Nineteen-millimeter prosthetic aortic valves allow normalization of left ventricular mass in elderly women. Ann Thorac Surg. 2002;74: 2022-5.

18. Sawant D, Singh AK, Feng WC, Bert AA, Rotenberg F. Nineteenmillimeter aortic St. Jude Medical heart valve prosthesis: up to sixteen years' follow-up. Ann Thorac Surg. 1997;63:964-70.

19. Rosenhek R, Binder T, Porenta G, Lang I, Christ G, Schemper M, et al. Predictors of outcome in severe, asymptomatic aortic stenosis. N Engl J Med. 2000;343:611-7.

20. Nashef SA, Roques F, Michel P, Gauducheau E, Lemeshow S, Salamon R. European system for cardiac operative risk evaluation (EuroSCORE). Eur J Cardiothorac Surg. 1999;16:9-13.

21. Devereux RB, Reichek N. Echocardiographic determination of left ventricular mass in man. Anatomic validation of the method. Circulation. 1977;55:613-8.

22. Medalion B, Lytle BW, McCarthy PM, Stewart RW, Arheart KL, Arnold JH, et al. Aortic valve replacement for octogenarians: are small valves bad? Ann Thorac Surg. 1998;66:699-706.
23. Blackstone EH, Cosgrove DM, Jamieson WR, Birkmeyer NJ, Lemmer JH $\mathrm{Jr}$, Miller DC, et al. Prosthesis size and long-term survival after aortic valve replacement. $J$ Thorac Cardiovasc Surg. 2003;126:783-96.

24. Bloomstein LZ, Gielchinsky I, Bernstein AD, Parsonnet V, Saunders C, Karanam R, et al. Aortic valve replacement in geriatric patients: determinants of in-hospital mortality. Ann Thorac Surg. 2001;71:597600 .

25. Ellis JT, Yoganathan AP. A comparison of the hinge and the nearhinge flow fields of the St. Jude Medical Hemodynamic Plus and Regent bileaflet mechanical heart valves. J Thorac Cardiovasc Surg. 2000;119:83-93.

26. Bach DS, Sakwa MP, Goldbach M, Petracek MR, Emery RW, Mohr FW. Hemodynamics and early clinical performance of the St. Jude Medical Regent mechanical aortic valve. Ann Thorac Surg. 2002;74: 2003-9.

27. Nidorf SM, Picard MH, Triulzi MO, Thomas JD, Newell J, King ME, et al. New perspectives in the assessment of cardiac chamber dimensions during development and adulthood. J Am Coll Cardiol. 1992; 19:983-8.

28. Vandervoort PM, Greenberg NL, Powell KA, Cosgrove DM, Thomas JD. Pressure recovery in bileaflet heart valve prostheses. Localized high velocities and gradients in central and side orifices with implications for Doppler-catheter gradient relation in aortic and mitral position. Circulation. 1995;92:3464-72.

29. Krayenbuehl HP, Hess OM, Monrad ES, Schneider J, Mall G, Turina M. Left ventricular myocardial structure in aortic valve disease before, intermediate, and late after aortic valve replacement. Circulation. 1989;79:744-55.

30. Ruel M, Rubens FD, Masters, RG, Pipe AL, Bedard P, Hendry PJ, et al. Late incidence and predictors of persistent or recurrent heart failure in patients with aortic prosthetic valves. J Thorac Cardiovasc Surg. 2004; $127: 149-59$

\section{JTCVS On-Line Manuscript Submission and Review}

Please visit http://www.editorialmanager.com/jtcvs/

Effective September 15, 2001, authors and reviewers may submit manuscripts and reviews electronically via Editorial Manager, our new Web-based system with full electronic submission, review, and status update capabilities.

As we move from paper to electronic submissions, the Editorial Office will make proxy submissions of all manuscripts accompanied by a diskette containing the electronic files of the text, tables, and figures. Editors, authors, and reviewers will receive automatic e-mails when significant events occur.

We strongly encourage all authors and reviewers to use Editorial Manager. Although we will continue to accommodate the submission of paper manuscripts for some months, our goal is to be completely electronic within 9 to 12 months.

All individuals currently in our database for whom we have e-mail addresses will receive via e-mail a system-assigned username and password that can be used to log in to the system without prior registration. All those not receiving the e-mail must register the first time they use the system.

As with any broad systemic change, the conversion to the new system will take some time to complete. We ask your patience as we replace our in-office database with the new system. We also encourage you to take advantage of the speed and efficiency that the new system will provide for us all: editor, author, reviewer, and publisher. 